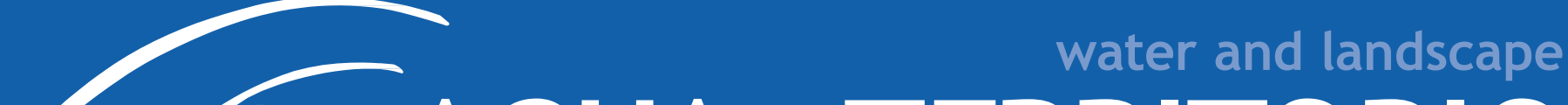 AGUA YTERRITORIO
}

\section{Gestión del agua y relaciones de poder en América Latina}

\author{
Water management and power relations in Latin America
}

\author{
Gonzalo Hatch Kuri \\ Universidad Nacional Autónoma de México \\ Ciudad de México, México \\ ghatch@comunidad.unam.mx \\ https://orcid.org/0000-0002-5189-4708 \\ Wagner Costa Ribeiro \\ Universidad de São Paulo \\ São Paulo, Brasil \\ wribeiro@usp.br \\ https://orcid.org/0000-0002-3485-9521
}

Un número importante de conflictos por el agua en América Latina se enmarcan dentro del contexto de una disputa política e ideológica suscitada por sectores que defienden la participación activa de las fuerzas del mercado en la reestructuración institucional del sector hídrico, situación que se ha fortalecido por los diversos procesos paulatinos de desregulación y pérdida de la rectoría del Estado en el sector. En contraposición, otros sectores como los movimientos sociales, exigen el reconocimiento del agua como un bien común y abogan por su protección y conservación ambiental, así como garantizar el Derecho Humano al Agua y al Saneamiento.

A pesar de que la privatización de los servicios de agua y saneamiento creció en la década de 1990, incluso en América Latina, hay un retorno a la gestión estatal. Una serie de fallas de las empresas privadas, que se resumen en un aumento de las tarifas, una disminución de la calidad del agua ofrecida y la falta de garantía de acceso universal a la población asistida, permitió cuestionar este modelo de gestión del agua.

En esa tesitura, una de las dimensiones que requiere estudiarse con mayor rigurosidad es la expresión territorial de los conflictos por el agua y sus múltiples dimensiones escalares en las que se conjugan distintas formas de ejercer el poder y el control político en el sector hídrico. Estos conflictos son cada vez más frecuentes debido al aumento y la presencia de actores e intereses que entran en disputa, como resultado de las transformaciones derivadas de las reformas que los Estados han aplicado a su sector hídrico nacional.

El reacomodo interno y externo de intereses sobre el agua ha permitido que nuevos actores exijan el control sobre esta, configurando disputas y conflictos en torno a un paradigma emergente de gestión, en el que se pretende privilegiar la participación del sector privado, sobre todo el transnacional (Gobernanza del Agua). En este sentido, dos dimensiones poco exploradas por la literatura especializada de los conflictos por el agua son, por una parte, la disputa por el control del agua subterránea y, por otra, el conflicto y la cooperación en la gestión de las aguas transfronterizas.

El esquema del ciclo hidrológico explica que la distribución físico-natural del agua es heterogénea, así el $97 \%$ del agua dulce continental físicamente accesible está constituida por agua subterránea y, sí se excluyen los glaciares y casquetes polares (físicamente no accesibles), el restante $0,1 \%$ es agua superficial localizada en las cuencas hidrológicas y sumamente comprometida por el creciente deterioro de su calidad. Empero, los lineamientos y directrices de la gestión del agua, continúan impulsando una visión de carácter técnica y despolitizada, sobre todo en lo que refiere al agua subterránea, evitando al máximo que se le identifique como una fuente de control y de 
ejercicio del poder político y económico. La importancia del agua subterránea, no solo se revela por su calidad y cantidad superior en comparación a las condiciones que caracterizan a los cursos de agua superficiales, también por la capacidad que posee esta para producir conflictos de poder en los que se revelan las asimetrías existentes entre sus usuarios. El control económico del agua subterránea, por ejemplo, lo ostentan los usuarios aglutinados en sectores como la industria embotelladora, minera, el sector agrícola que produce para el mercado mundial, los sistemas privatizados de agua potable y saneamiento, por citar algunos de los más notables.

Una comprensión cabal de la distribución desigual y político-espacial del agua subterránea en América Latina, exige abarcar desde los análisis de las implicaciones de los esquemas diseñados para su evaluación científica, las características de sus marcos regulatorios y, el estudio crítico de la política de los derechos de agua en cada jurisdicción. Sin duda, el reto es visibilizar en el debate académico y público, los argumentos que explican por qué a esta agua se le continúa posicionando como un tema despolitizado y absolutamente carente de prestigio social alguno. En este sentido, un ejemplo tácito son los conflictos por las aguas transfronterizas, particularmente, las aguas subterráneas transfronterizas. Se considera que alrededor del $60 \%$ del agua dulce superficial es atravesada por una frontera internacional y que cerca del $40 \%$ está gobernada por algún tipo de acuerdo o tratado legal, pero estos datos marginan los más de 592 acuíferos transfronterizos que se han inventariado a la fecha por organismos supranacionales.

Este dossier conjunta seis artículos de investigación que contribuyen al análisis interdisciplinario de los conflictos por el agua en América Latina, los cuales se caracterizan por un riguroso análisis crítico de las condiciones e implicaciones que se desprenden de los ineficaces esquemas de gestión del agua que establecen las condiciones para acceder a esta, situación que configura disputas entre el Estado y los usuarios del agua, revelando las asimetrías en su acceso, distribución y consumo final.

Así, en primer lugar, Tanya García y Eva Carazo, plantean que en Costa Rica se elevó rango constitucional el Derecho Humano al Agua Potable en el 2003, pero la falta de consenso entre los diferentes actores ha evitado la aprobación de una nueva ley del agua. Las autoras concluyen que el principal desafío que enfrenta ese país es que la ley garantice la gestión integrada del sector hídrico, la participación ciudadana y la protección del ambiente, pero, sobre todo, que los servicios de agua potable y saneamiento mantengan su carácter público.

En segundo lugar, la contribución de Maureen Walschot, investiga los factores que han incidido en la ralentización de la entrada en vigor del Acuerdo sobre el Acuífero Guaraní suscrito por Argentina, Brasil, Paraguay y Uruguay en agosto de 2010. La autora concluye que la consolidación de una autoridad de gestión real para ese acuífero es consecuencia directa de la cesión de cierta soberanía exclusiva sobre el acuífero, situación que tensiona la cooperación entre los países miembros y, al mismo tiempo, cuestiona la unidad latinoamericana.

México es objeto de análisis en dos contribuciones que refieren problemas derivados del esquema actual de gestión oficial del agua subterránea. Por una parte, Edgar Talledos y Verónica Ibarra, desde la geografía explican los factores que han incidido en la concentración de las concesiones de agua subterránea entre pocos usuarios, por medio del análisis de tres estudios de caso. Concluyen que una condición a priori que ha fomentado tal problema, son las condiciones favorables de infraestructura que los usuarios han desarrollado previamente para el aprovechamiento de esa fuente de abastecimiento, lo cual ha servido para cimentar las diferentes políticas sectoriales económicas de los últimos gobiernos federales. Por otra parte, el trabajo de Elia Méndez-García, analiza una dimensión del conflicto por el agua subterránea en Valles Centrales de Oaxaca, poco explorada hasta ahora: el uso de la semántica como recurso lingüístico de defensa de los derechos de agua indígenas, en oposición a la política autoritaria del agua subterránea. Así, concluye que las capturas semánticas requieren un cambio de lugar, para evitar que el Estado desmantele e inactive el movimiento social indígena, por ello es necesaria la renovación creativa de la semántica que facilite la construcción de autonomías políticas en el conflicto por el acceso al agua.

Desde el Perú, Percy A. Bobadilla, sostiene que los conflictos por el agua pueden estudiarse desde variables como el análisis crítico de los discursos del desarrollo regional. En su estudio de caso en Cajamarca, refiere que los intereses de la minería y el gobierno nacional se escudan en un modelo de desarrollo sostenible, pero con énfasis en la gran inversión, mientras que el modelo alternativo que se basa en la diversificación económica y el ordenamiento territorial, es defendido por la sociedad civil y el gobierno regional. El autor concluye, que, en la polarización de los discursos, se revela que la minería sostenible no logró encausar un modelo legítimo del uso del agua para este sector.

Finalmente, el dossier cierra con el artículo de Shirley Capela Tozi, quien plantea una visión panorámica de los conflictos por el agua en la ciudad de Belém do Para, Brasil, puerta de entrada al Amazonas en la que, paradójicamente, los conflictos por el agua no se deben a su relativa abundancia, sino a un inadecuado sistema de gestión que se revela en conflictos que se explican por la infraestructura desarrollada para evitar los daños por la abundancia de agua, lo que ha encarecido el agua para nuevos sectores de la población y sectores productivos emergentes.

En suma, este dossier ofrece apenas una pequeña muestra de los conflictos por el agua en América Latina, con énfasis en el agua subterránea y las aguas transfronterizas, desde diferentes enfoques y tratamientos académicos, los cuales proveen evidencias novedosas que enriquecen la temática aquí tratada. 